\title{
Demonstration Model Circuit Panel for Silicon-on-Insulator Microelectronics and Flat-Panel 1994 LDRD Final Report \\ 94-FS-041
}

Anthony McCarthy

September 1995

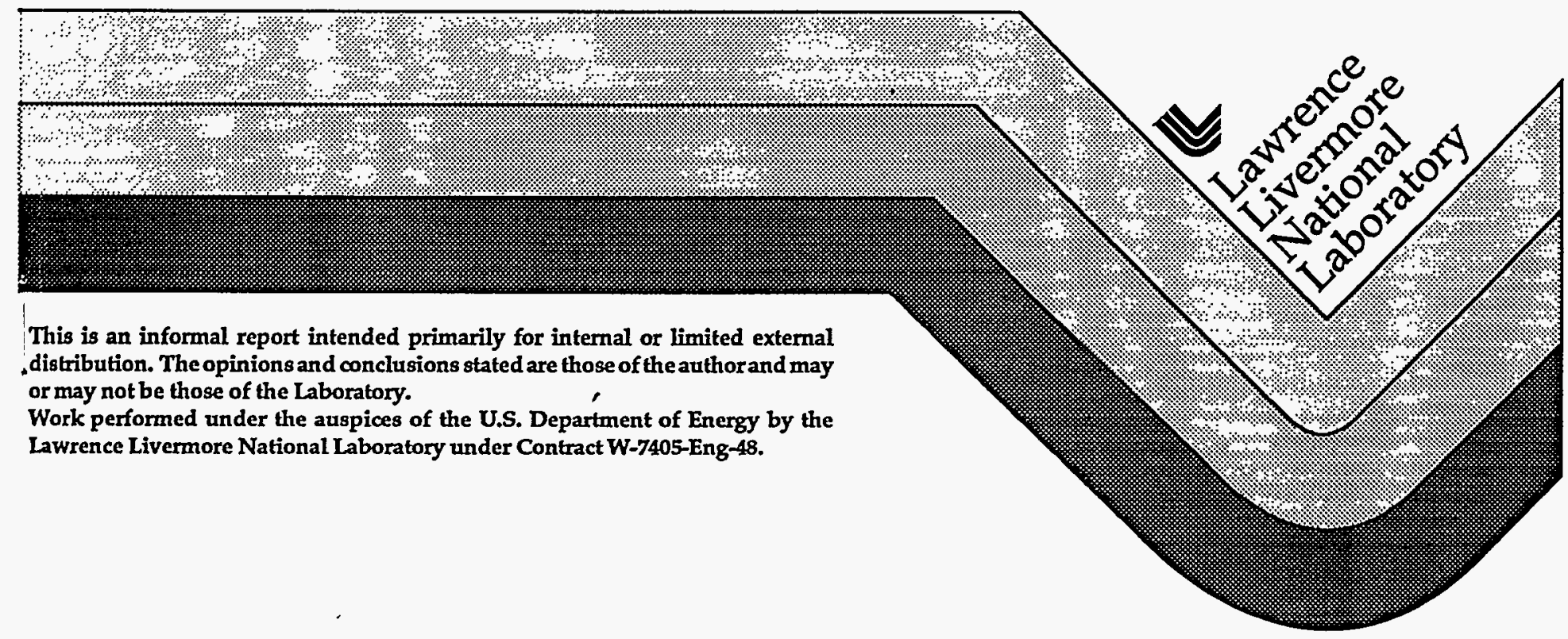




\section{DISCLAIMER}

This document was prepared as an account of work sponsored by an agency of the United States Government. Neither the United States Government nor the University of California nor any of their employees, makes any warranty, express or Implied, or assumes any legal liability or responsibility for the accuracy, completeness, or usefulness of any information, apparatus, product, or process disclosed, or represents that its use would not infringe privately owned rights. Reference herein to any specific commercial products, process, or service by trade name, trademark, manufacturer, or otherwise, does not necessarily constitute or imply its endorsement, recommendation, or favoring by the United States Government or the University of California. The views and opinions of authors expressed herein do not necessarily state or reflect those of the United States Government or the University of California, and shall not be used for advertising or product endorsement purposes.

This report has been reproduced directly from the best available copy.

Available to DOE and DOE contractors from the Office of Scientific and Technical Information P.O. Box 62, Oak Ridge, TN 37831

Prices available from (615) 576-8401, FTS 626-8401

Available to the public from the

National Technical Information Service

U.S. Department of Commerce 5285 Port Royal Rd. Springfield, VA 22161 


\title{
LDRD 94 Final Report \\ Demonstration Model Circuit Panel for Silicon-on-Insulator Microelectronics and Flat-Panel
}

\author{
Anthony McCarthy \\ Principal Investigator \\ 94-FS-041
}

\begin{abstract}
.
Crystalline silicon wafers are frontside bonded to glass substrates. The silicon substrate is removed and thin films of silicon remain on the insulating substrates. The performance of devices formed in the thin films before bonding are compared with those after bonding.

\section{Background}

The gate density of silicon microelectronics has been increasing by a factor of 2 every two years. This blitz-like rate of technological change demands an ever increasing range of creativity and ingenuity to sustain. Perhaps the principle determining factor is the rate of improvement in lithographic definition. During 1994, many silicon fabrication facilities are manufacturing using half-micron design rules. A second area of technological change is the gradual adoption of silicon-on-insulator (SOI) substrates as a respected, albeit expensive, starting material. Another area, gaining increasing interest, is flat-panel display technology which is a cousin of SOI since the electronics for many displays are fabricated on insulating substrates, usually glass. Finally, there has been explosive growth in the area of silicon micromachining using the many sophisticated and highly developed patterning and etching methodologies in silicon fabrication. It is in the latter two areas where the present work will see its primary impact.

Manufacturing crystalline silicon electronics on insulating substrates has been an almost perennial goal among silicon aficionados. Several technologies are currently available such as SIMOX (separation by implanted oxygen), bonded wafers, and PACE (plasma assisted chemical etching). The downside of these technologies is that 4 inch substrates typically cost $\$ 400$ each, a $40 x$ charge difference from bulk silicon costs of $\$ 10$ per wafer. In the display arena, the use of amorphous (a-Si) silicon on low quality glass, and polysilicon ( $\mathrm{p}-\mathrm{Si}$ ) on quartz, has been pioneered by many companies. The Japanese have mastered the use of a-Si for passive matrix liquid crystal displays (AMLCD) and Xerox is one of the many competitors in the polysilicon technology. The use of a-Si is limited since transistors made using this material exhibit mobilities less than $1 \mathrm{~V} \mathrm{~cm} / \mathrm{sec}$. This has the consequence that liquid crystal displays cannot have native electronic drivers but must be supported by external electronics manufactured separately from the a-Si, requiring significant extra expense and connection cost. The principal limit of polysilicon is its restriction to quartz substrates and secondarily its grain size which in turn limits the smallest transistor which can be made in this technology. The principal reason why crystalline silicon (c-Si) is not used on insulating substrates is the incompatibility of silicon processing temperatures with most glass materials except quartz. In general silicon-onquartz (SOQ) has not been pursued for reasons of expense, and difficulty in forming thin films of SOQ.

In this work, the feasibility of combining thin-film crystalline silicon microelectronics on low cost glass substrates was pursued. These low-cost glass substrates are of the type used in flat-panel applications and are of the type Corning 7059. There were two chief motivations. The first was the possibility of combining silicon microelectronics with sensor applications simultaneously on the same substrate and the second was to demonstrate the performance of crystalline microelectronics on cheap glass for display purposes.
\end{abstract}




\section{Sample Preparation}

The experimental plan is to form silicon transistors on suitably prepared substrates, bond the wafer frontside to the glass substrate, remove the silicon substrate with a wet potassium hydroxide etch, and peel the remaining silicon to reveal the circuits and devices. Four inch p-type $\langle 100\rangle$ silicon wafers are selected with doping concentration of about $1 \mathrm{e} 15 / \mathrm{cm}^{3}$. A thin thermal oxide is grown on the wafers. The alignment tool used throughout this work is an Ultratech 1X stepper, model 1000 and a pre-existing mask series was used to perform the process sequence. Alignment targets are defined by performing the first lithography and exposing target crosses on the wafer. The oxide is etched for 1 minute in 20/1 buffered hydrofluoric acid (BHF) and the silicon is etched in a $\mathrm{SF}_{6} / \mathrm{CClF} 5$ atmosphere for 30 seconds to form a $1000 \AA$ trench and the resist is stripped. A $4500 \AA$ field oxide is thermally grown at $1000^{\circ} \mathrm{C}$. An isolation pattern is formed in photoresist and the field oxide is etched. The resist is stripped and a thin $400 \AA$ thermal oxide is grown at $900^{\circ} \mathrm{C}$. The source and drain regions are patterned and implanted with $3 \mathrm{e} 15$ Arsenic at $100 \mathrm{keV}$. The resist is stripped and the thin oxide is completely removed in a $6 / 1$ BHF solution after 45 seconds. The wafers are RCA cleaned and oxidized in a dry oxygen atmosphere at $1000^{\circ} \mathrm{C}$ for 48 minutes. The contact holes are defined and etched. The resist is stripped and the wafers are dipped for 30 seconds in 50/1 dilute HF before insertion in a metal sputterer. $2000 \AA$ of $\mathrm{Al} / 1 \% \mathrm{Si}$ is deposited. A metal lithography and etch is performed. The resist is stripped and the wafers are cleaned and placed in a forming gas anneal tube at $350^{\circ} \mathrm{C}$ for 15 minutes. The transistors are tested and IV characteristics stored for later comparison to measurements taken after bonding and substrate removal.

\section{Bonding}

A Corning 7059 four inch diameter glass disk, of similar shape to a silicon wafer, is cleaned. The glass disk is glued to the frontside of the silicon wafer using a UV curable epoxy. The two substrates are spaced apart by three small-area 4 mil thick silicon shims. The adhesive is introduced by capillary action.

\section{Thinning}

The next stage is the removal of the silicon substrate leaving the thin film of silicon remaining on the glass substrate. This is achieved by placing the assembly in a heated potassium hydroxide solution at $75^{\circ} \mathrm{C}$ for eight hours until the remaining silicon thickness is about $10-20 \mu \mathrm{m}$. The remaining silicon is peeled to reveal the circuits and devices remaining in silicon islands while the interconnect is protected by the original field oxide.

\section{Connections}

Electrical connections to the devices are established by dipping the substrate in an acid bath to remove a thin layer of thermal oxide exposing the interconnections while avoiding the etching of the metal lines. A suitable acid combination is commercially available as "Pad etch".

\section{Results and Discussion}

The devices are measured and the IV characteristics compared to those acquired before bonding. Figure 1 shows the drain current versus gate voltage plot of $24 \mu \mathrm{m}$ wide by $4 \mu \mathrm{m}$ long NMOS transistors before and after bonding with the drain voltage held at 5 volts. The characteristics are almost identical.

A plot of the forward characteristics of the same two devices is shown in figure 2. In this figure the drain current is plotted versus the drain voltage at fixed values of gate voltage of $-1,3$ and $-5 \mathrm{~V}$. The two IV plots demonstrate that devices before and after bonding can perform in a predictable and similar manner. 
This indicates that the transfer process has not affected the performance of the devices, the reverse leakage behaviour is ideal, and the forward characteristic indicates crystalline mobility levels have been easily achieved.

\section{Conclusions.}

This work has demonstrated the novel and surprising possibility of using thin-film crystalline silicon electronics on Corning 7059 glass. This may be achieved with a simple circuit technology while paying attention to the principal concerns of ease of transfer and manufacturability. This work may be extended to providing thin film silicon microelectronics on any substrate including plastics.

\section{DISCLAIMER}

This report was prepared as an account of work sponsored by an agency of the United States This report was prepared as an account of work sponsored by an agency of the United States employees, makes any warranty, express or implied, or assumes any legal liability or responsibility for the accuracy, completeness, or usefulness of any information, apparatus, product, or process disclosed, or represents that its use would not infringe privately owned rights. Reference herein to any specific commercial product, process, or service by trade name, trademark, manufacturer, or otherwise does not necessarily constitute or imply its endorsement, recommendation, or favoring by the United States Government or any agency thereof. The views and opinions of authors expressed herein do not necessarily state or reflect those of the United States Government or any agency thereof. 

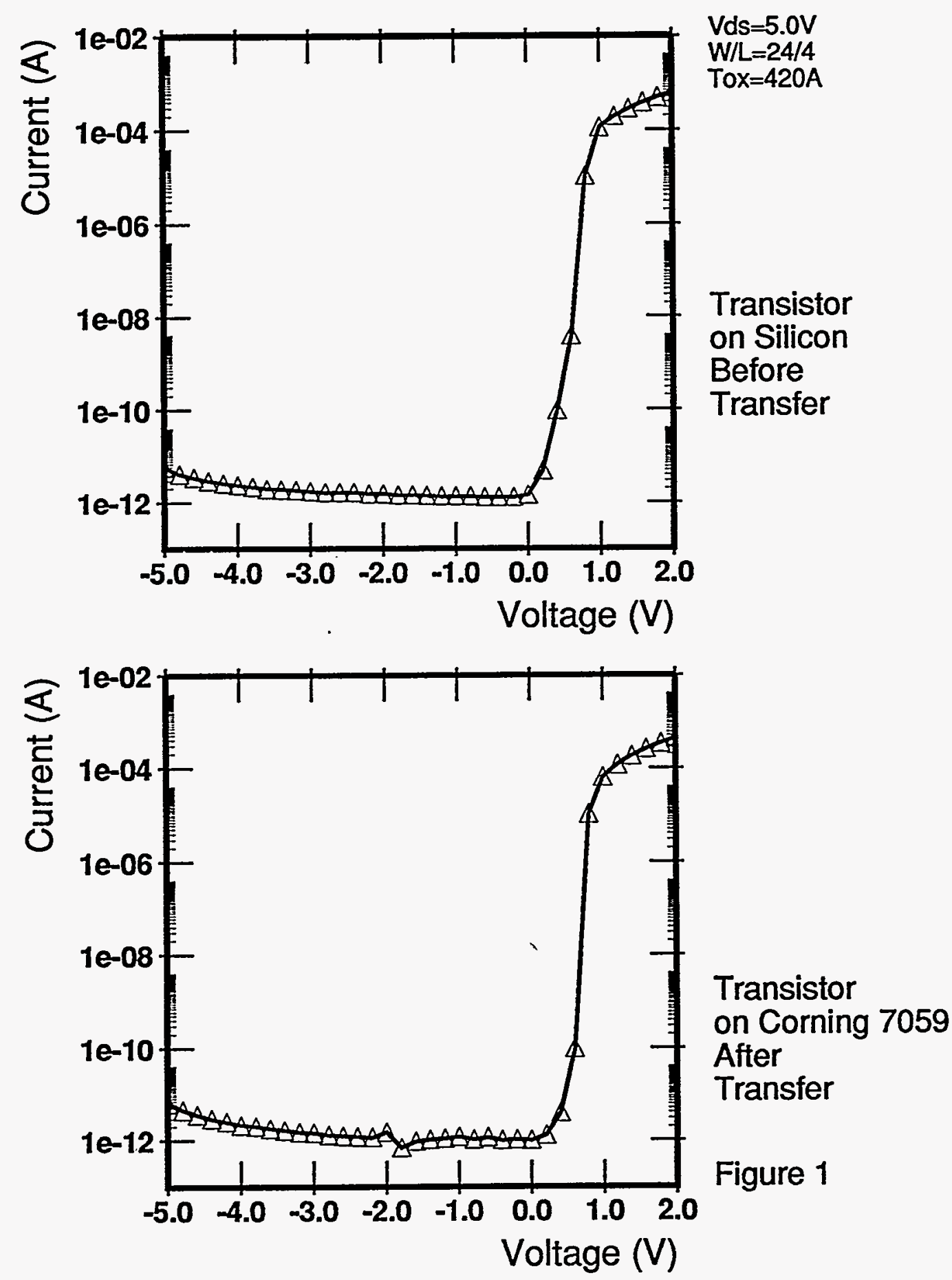

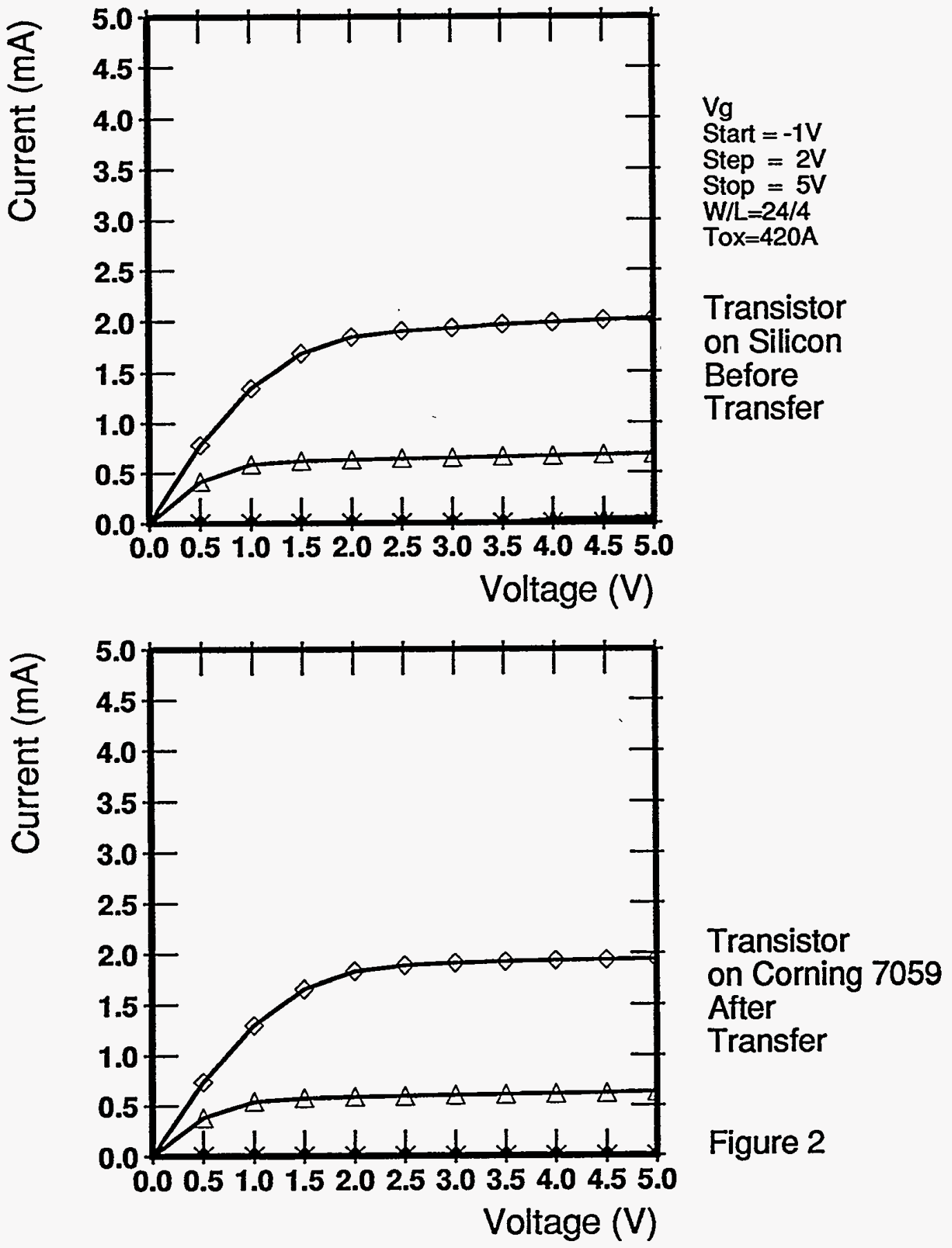
Technical Information Department - Lawrence Livermore National Laboratory University of California - Livermore, California 94551

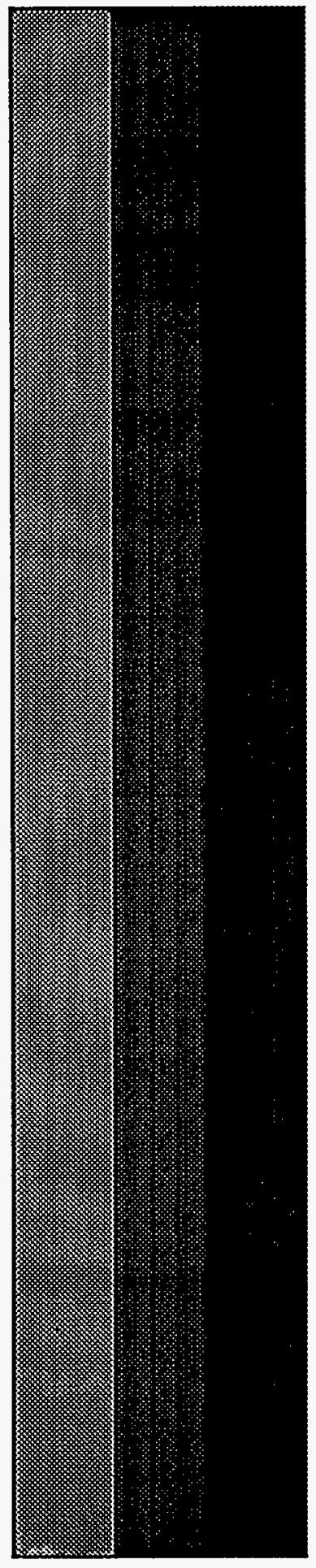

